DOI: $\underline{\text { https://doi.org/10.24867/15BE28Pantic }}$

\title{
IZBOR HIPERPARAMETARA ALGORITAMA DUBOKOG UČENJA SA POTKREPLJENJEM PRIMENOM GENETSKOG ALGORITMA
}

\section{SELECTION OF HYPERPARAMETERS OF DEEP REINFORCEMENT LEARNING ALGORITHMS USING A GENETIC ALGORITHM}

\section{Oblast - ELEKTROTEHNIKA I RAČUNARSTVO}

Kratak sadržaj - Ovaj rad rešava problem hoda robota u prostoru pomoću algoritama dubokog učenja sa potkrepljenjem koji se optimizuju pomoću genetskog algoritma.
\end{abstract}

Vasilije Pantić, Fakultet tehničkih nauka, Novi Sad

Ključne reči: Duboko učenje sa potkrepljenjem, genetski algoritam

Abstract - This paper solves the problem of robots walking in space using deep reinforcement learning algorithms that are optimized using a genetic algorithm.

Keywords: Deep Reinforcement Learning, Genetic Algorithm

\section{UVOD}

Veštačka inteligencija (eng. artificial intelligence - AI) ima za cilj pravljenje programa koji bi imitirao ljudska ponašanja i rezonovanje. $A I$ na osnovu prethodnog iskustva (podataka kojim ima pristup) pokušava da nađe šablon po kome su mapirani podaci tako da dolaskom novih podataka može da donosi odluku ili rezultat sličan tim podacima. AI zahteva ogromnu količinu podataka u odnosu na ljudski mozak, kome je potrebno nekoliko puta da ugleda dva različita objekta da zna da ih razlikuje, dok to sa $A I$-em nije slučaj.

Pored traženja šablona u podacima, postoji i način učenja donošenja odluka načinom kazni i nagrada. Kao što čovek teži u životu nagradama i pozitivnim stvarima, tako je i nad ovim pristupom cilj da se loše odluke penalizuju negativnom nagradom (kaznom), dok bi odluke koje vode ka željenim ciljevima davalo pozitivne nagrade.

Rad rešava problem kretanja robota (koji predstavlja repliku čoveka) sa ciljem da hodajući u prostoru održava ravnotežu i uspešno korača napred metodama nagrađivanja i kažnjavanja, izraženim kroz mašinsko učenje i pronaći optimalna rešenja u pogledu onih koja su najbolja i time postići maksimalne vrednosti i na najbolji način obučiti robota da hoda.

\section{IMPLEMENTACIJA REŠENJA}

\subsection{Uvod u problem i tehnologije}

Problem koji ovaj rad rešava pomoću algoritama dubokog učenja sa potkrepljenjem i genetskim algoritmom se tiče učenja robota hodu (eng. humanoid robot walk).

\section{NAPOMENA:}

Ovaj rad proistekao je iz master rada čiji mentor je bio dr Milan Rapaić, red. prof.
Okruženje koje se koristi za ovaj problem je predefinisan (nije pravljen od strane autora rada) i u pitanju je OpenAI Gym [4] i PyBullet Gym [5], koji daju gotovo okruženje u kome se robot nalazi, samog robota sa svojim akcijama koje može da izvršava, kao i sistem nagrađivanja i kažnjavanja.

Programski jezik iskorišten za implementaciju rešenja jeste Python sa radnim okvirom za duboko učenja PyTorch [6]. Na slici 1 dat je izgled robota i okruženja koji se rešava u ovom radu.

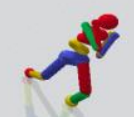

Slika 1. Primer robota i okruženja problema [5]

Cilj robota prilikom hoda jeste da se uspešno kreće u prostoru (prostor nema prepreke). Stanje prostora u kome se robot nalazi je predstavljeno kao niz veličine 44 popunjen vrednostima od -1 do 1 gde ti brojevi prezentuju ugao i poziciju zglobova robota. Kao akcije koje robot vrši u ovom prostoru, prezentovane su kao niz veličine 17 popunjen vrednostima od -1 do 1 gde ti brojevi predstavljaju momente sile primenjene na zglobove. Po pitanju nagrađivanja robota za uspešne akcije, robot ostvaruje nagradu onda kada se pomera unapred i kada protivi teži gravitacije.

Formalnije izraženo, cilj je pronaći politiku $\pi$ kojom će agent postizati maksimalnu kumulativnu nagradu nad trajektorijom, tačnije da će povrat jedne epizode biti maksimalan. Robot počinje iz početnog stanja $S_{0}$ te je cilj izvršavati akcije koje će omogućiti robotu da ne završi u neželjenom terminalnom stanju, koje zapravo predstavlja njegov pad.

Da bi za ovo rešenje postojalo željeno terminalno stanje, određen je maskimalan broj akcija koje agent može izvršiti u jednoj epizodi, tako da se sada problem odnosno kriterijum definiše kao postizanje maskimalnog broja akcija koje agent može izvršiti.

Algoritmi koji se koriste za rešavanje ovog problema su $P P O$ [3] i TRPO [1], dok se genetski algoritam koristi za optimizaciju hiperparametara nad algoritmima tako da se ostvari bolji i brži rezultat. Sav kod implementacije rešenja problema se nalazi na [7] i [8]. 


\subsection{Implementacija neuronskih mreža}

Oba algoritma dubokog učenja sa potkrepljenjem (TRPO i $P P O)$ koriste neuronske mreže da aproksimiraju politiku i funkciju vrednosti stanja. Neuronska mreža koja aproksimira politiku naziva se glumac (eng. actor), a neuronska mreža koja aproksimira funkciju vrednosti stanja se naziva kritičar (eng. critic).

Ideja pristupa sa glumcem i kritičarem jeste da kritičar aproksimira funkciju vrednosti za celi prostor na osnovu nagrada koje agent ostvaruje vršeći trajektorije $u$ datom prostoru odnosno na osnovu dosadašnjeg iskustva, dok je cilj glumca da ažurira parametre politike i aproksimira politiku agenta u pravcu sugerisanom od strane kritičara.

Obe arhitekture neuronskih mreža imaju isti ulaz u mrežu - niz veličine 44 koji prezentuje stanje u kome se agent trenutno nalazi.

Broj skrivenih slojeva za obe arhitekture je 2, sa brojem neurona po sloju 128 i 64 redom. Jedina razlika između ove dve arhitekture jeste u dimenziji izlaznog sloja, koji za glumca ima 17 neurona u izlaznom sloju da predstavi akciju koju treba agent da izvrši u datom stanju, dok kritičar ima samo jedan neuron $u$ izlaznom sloju da predstavi funkciju vrednost tog stanja. Obe arhitekture kao aktivacionu funkciju (osim nad izlaznim slojem) koriste $R e L U$ aktivacionu funkciju.

Kako je u pitanju kontinualan prostor akcija koje agent $\mathrm{i}$ izvršava i kako se očekuje da vrednosti vektora koji se prosleđuje kao akcija ima vrednosti u intervalu $[-1,1]$, tako se za izlaz glumca koji treba da proizvede sledeću akciju koristi Gaussova MultivariateNormal distribucija [9], koja se zapravo brine da izlaz iz neuronske mreže baš daje takve vrednosti, postavljajući srednju vrednost distribucije na izlaze neuronske mreže glumca.

\subsection{Implementacija algoritama dubokog učenja sa potkrepljenjem}

Hiperparametri koji su od interesa konkretno za TRPO algoritam [1] i koji su bitni za adekvatno treniranje samog algoritma na zadatom problemu su sledeći:

- delta: ograničenje KL-divergencije

- gamma: faktor obezvređivanja nagrada

- cg_delta: ograničenje za conjugate gradient algoritam [2]

- cg_iterations: broj maksimalnih iteracija za conjugate gradient algoritam [2]

- alpha: koeficijent za računanje pravilnog gradijenta da zadovolji delta koeficijent

- backtrack_steps_num: maskimalan broj koraka kojim se ide unazad za računanje pravilnog gradijenta da zadovolji delta koeficijent

- critic_epoch_num: broj epoha za treniranje kritičara za jednu epohu TRPO algoritma

Implementacija TRPO algoritma data je na [7]. Kod TRPO, neuronska mreža kritičar se ažurira gradijentnim spustom sa ciljem da estimira funkciju vrednosti stanja, dok neuronska mreža glumac računa manuelno gradijent kao maksimalni korak koji unapređuje politiku, a zadovoljava ograničenje dozvoljene razlike stare i nove politike, tačnije delta.

Hiperparametri koji su od interesa konkretno za $P P O$ algoritam [3] i koji su bitni za adekvatno treniranje samog algoritma na zadatom problemu su sledeći:
- number_of_network_updates_per_iteration: broj epoha za treniranje kritičara i glumca za jednu epohu PPO algoritma

- discounting_factor: faktor obezvređivanja nagrada

- clip_range: specifično ograničenje koje ograničava

koliko stara i nova politika mogu da se razlikuju

Implementacija PPO algoritma data je na [7]. Kod PPO, neuronska mreža kritičar se ažurira gradijentnim spustom sa ciljem da estimira funkciju vrednosti stanja, dok neuronska mreža glumac se ažurira gradijentnim usponom sa ciljem da estimira politiku agenta.

\subsection{Implementacija genetskog algoritma}

Ideja genetskog algoritma za problem jeste da nađe optimalne parametre za TRPO algoritam [1] (s obzirom da je to algoritam sa više parametara, te zahteva više eksperimentisanja i podešavanja), te je cilj pronaći kandidata koji postiže najbolje performanse $u$ prvih nekoliko desetina epoha nad problemom.

Hiperparametri koji se tiču konkretno genetskog algoritma su sledeći:

- number_of_agents: broj kandidata po generaciji

- number_of_generations: maksimalan broj generacija

koje će genetski algoritam da produkuje

- number_of_iterations: broj epoha TRPO algoritma

koje će jedan kandidat da izvrši u generaciji

- top_limit_agents: broj elitnih kandidata za prenos u sledeću generaciju

- mutation_chance: šansa da će detetovi genomi biti mutirani

Kao fitnes funkcija svakog kandidata se gleda rewards-togo koje je ostvario kroz number_of_iterations broja epoha, sa dodatkom da se prvo stanje (početno) postavlja na nulu jer je nasumično i ne igra ulogu.

Za inicijalizaciju populacije, ideja je nasumično dodeliti vrednosti parametara koje želimo da optimizujemo.

Za selekciju roditelja, ideja je da dva roditelja uvek kreiraju dva deteta, koja će imati drugačiji način ukrštanja, sa ciljem razlikovanja među decom. Svaki roditelj ima šansu, ali bolju šansu dobijaju roditelji sa boljom vrednošću fitnes funkcije. Prvo se na osnovu vrednosti fitnes funkcije poredaju u rang (od 1 koji je najbolji do number_of_agents koji je sa najmanjom fitnes vrednošću), te se svaki od njih množi sa nasumičnim brojem iz uniformne distribucije od 0 do 1 . Za kraj se nad ovim brojevima vrši softmax [10]. Onda se na osnovu šanse tih brojeva biraju roditelji (moraju biti različita).

Za mutaciju genotipa dece, na osnovu mutation_chance se odlučuje da li će se detetovi genotipi mutirati ili ne (predstavlja broj između 0 i 1). Dete se mutira tako što se uzme nasumičan broj iz uniformne distribucije između $0 \mathrm{i}$ 1, koji ima za cilj da promeni vrednosti kandidatskih parametara u rasponu $-10 \%$ do $+10 \%$ u zavisnosti od nasumičnog broja.

Za ukrštanje genotipa roditelja, ideja je takva da se nađe nasumičan broj iz uniformne distribucije između 0 i 1 i primene sledeće formule za ukrštanje dva deteta koje dva roditelja stvaraju za genotipe dece

newParam $1=$ param $1 * c+$ param $2 *(1-c)$ newParam $2=\operatorname{param} 2 * c+$ param $1 *(1-c)$ 
Za elitne kandidate, biraju se direktno oni koji imaju najveći fitnes rezultat, broj elitnih kandidata definisan je prema top_limit_agents parametru. Elitni kandidati prelaze u novu generaciju netaknuti, odnosno ne prolaze kroz proces mutiranja.

Za kreiranje nove generacije se koriste tehnike kreiranja novih kandidata standardnim putem ukrštanja i mutiranja preko roditelja, a ostatak se popuni elitnim kandidatima, tako da veličina populacije iz generacije u generaciju ostane ista.

\section{EKSPERIMENTI I REZULTATI}

Za adekvatno treniranje algoritama dubokog učenja sa potkrepljenjem potrebni su i adekvatni hiperparametri koji će algoritam da dovedu do zadovoljavajućeg rešenja. $\mathrm{Za}$ treniranje TRPO algoritma [1], korišteni su hiperparametri dati u tabeli ispod. Naime, ovi parametri birani su eksperimentisanjem i isprobavanjem, kao i upotrebom preporučenih vrednosti koji za većinu problema radi zadovoljavajuće.

\begin{tabular}{|c|c|}
\hline \multicolumn{2}{|c|}{ TRPO hiperparametri } \\
\hline Ime parametra & Vrednost parametra \\
\hline learning_rate & $2.5^{*} 10^{-4}$ \\
\hline delta & {$\left[3 * 10^{-1}, 3 * 10^{-2}, 3 * 10^{-3}, 3 * 10^{-4}\right]$} \\
\hline cg_delta & $1 * 10^{-2}$ \\
\hline cg_iterations & 10 \\
\hline alpha & 0.99 \\
\hline backtrack_steps_num & 100 \\
\hline critic_epoch_num & 20 \\
\hline num_of_timesteps & 4800 \\
\hline max_timesteps_per_episode & 1600 \\
\hline gamma & 0.99 \\
\hline num_of_epochs & 40900 \\
\hline mean_episode_reward & $\sim 526$ \\
\hline time_for_training(days) & 10 \\
\hline
\end{tabular}

Prilikom treniranja TRPO algoritma, pojavljuju se dva glavna problema:

- potreba da se delta hiperparametar menja u toku treniranja, jer na početku treniranja odgovara veća vrednost (ako zadržimo manju, učenje ide sporo do nivoa da se i ne trenira), dok posle nekog vremena zahteva manju vrednost jer se zahteva manji region poverenja radi optimalnijeg treniranja (ako zadržimo veliku vrednost, očekivani povrat epizoda po epohama ili stagnira ili opada)

- dugotrajan proces obučavanja, koji ukazuje na to da hiperparametri mogu bolje biti optimizovani tako da je proces manji

Grafici treniranja i prosečnog povrata po epohama TRPO algoritma dati su na [7].

$\mathrm{Za}$ treniranje $P P O$ algoritma [3], korišteni su hiperparametri dati u tabeli ispod. Naime, ovi parametri birani su eksperimentisanjem i isprobavanjem, kao i upotrebom preporučenih vrednosti koji za većinu problema radi solidno.

\begin{tabular}{|c|c|}
\hline \multicolumn{2}{|c|}{ PPO hiperparametri } \\
\hline Ime parametra & Vrednost parametra \\
\hline learning_rate & $2.5^{*} 10^{-4}$ \\
\hline num_of_timesteps & 4800 \\
\hline max_timesteps_per_episode & 1600 \\
\hline critic_epoch_num & 20 \\
\hline gamma & 0.99 \\
\hline clip_range & 0.2 \\
\hline num_of_epochs & 9000 \\
\hline mean_episode_reward & $\sim 558$ \\
\hline time_for_training (days) & 2 \\
\hline
\end{tabular}

PPO kao algoritam za dati problem se umnogome pokazao kao bolji izbor. U slučaju ovog algoritma, nema potrebe za manuelnim menjanjem parametara, niti za dugim obučavanjem. Grafici treniranja i prosečnog povrata po epohama PPO algoritma dati su na [7].

$\mathrm{S}$ obzirom na napomenute probleme koji se javljaju kod TRPO algoritma, cilj je sada inkorporirati pristup genetskog algoritma tako da potencijalno reši nedostatke koji se javljaju prilikom obučavanja TRPO algoritma na ovom problemu. Cilj genetskog biće da pronađe optimalne hiperparametre koji će dovesti do efikasnijeg treniranja i rešiti navedene probleme.

Kod TRPO algoritma, jedini hiperparametar koji zahteva da se manuelno menja tokom treniranja jeste delta, i to na opadajući način. Ideja je predstaviti delta kao kvadratnu funkciju koja opada u zavisnosti od trenutnog broja epohe na način:

$$
\text { delta }=\frac{1}{\text { deltaa } 2 * n^{2}+\text { deltaa } 1 * n+\operatorname{deltaa} 0}
$$
gde je $n$ broj trenutne epohe, a parametri deltaa2, deltaa1, deltaa 0 ciljani parametri za optimizaciju nad genetskim algoritmom.

Za treniranje genetskog algoritma, korišteni su hiperparametri dati u tabeli ispod. Naime, ovi parametri birani su eksperimentisanjem i isprobavanjem, kao i upotrebom preporučenih vrednosti koji za većinu problema radi solidno. Konkretan parametar number of iterations je odabran na datu vrednost kao najbolji odnos vremenske zahtevnosti obučavanja jednog kandidata i broja iteracija (epoha) koliko će jedan kandidat da se trenira.

\begin{tabular}{|c|c|}
\hline \multicolumn{2}{|c|}{ GA hiperparametri } \\
\hline Ime parametra & Vrednost parametra \\
\hline number_of_agents & 15 \\
\hline number_of_iterations & 70 \\
\hline top_limit_agents & 1 \\
\hline mutation_chance & 0.1 \\
\hline number_of_generations & 17 \\
\hline delta_a2 & 0.01487870062184785 \\
\hline delta_al & 0.0005061652202640241 \\
\hline delta_a0 & 8.163872665158063 \\
\hline time_for_training (days) & 4.5 \\
\hline
\end{tabular}


Rezultati koji su postignuti na optimizovanim hiperparametrima nisu bolji, čak su i znatno lošiji sa daljim epohama od onih koji se dobijaju sa menjanjem manuelno hiperparametra delta, a glavni razlog tome je što vrednost delta postaje premali posle nekog broj epohe (zato što je funkcija predstavljena pomoću nje), te se treniranje izvršava sporo, skoro pa nikako, što ne doprinosi rešenju efikasnosti i optimalnosti, dok je rešenje da se ne menjaju parametri tokom treniranja zadovoljeno. Ovakvim pristupom rešenje nikada ne bi konvergiralo ka krajnjem rešenju jer je vrednost delta premalo i sa sve većim brojem epoha bi težilo nuli odnosno nepostojećem regionu poverenja, tako da učenja nema.

Kao rešenje koje će dovesti do konvergencije, uzimajući u obzir prvobitni eksperiment nad TRPO algoritmom jeste promena funkcije koja opisuje deltu na sledeći način:

$$
\text { delta }=\max \left(\frac{1}{\operatorname{deltaa} 2 * n^{2}+\operatorname{deltaa} 1 * n+\operatorname{deltaa} 0}, \text { deltamin }\right)
$$

gde je sada deltamin jednak minimalnoj pozitivnoj vrednosti kojoj može parametar delta da bude jednak, u cilju prevencije premalih vrednosti.

Gledajući novi predlog delta funkcije, kao deltamin se može odabrati najmanja vrednost iz prvog eksperimenta nad TRPO algoritmom, a za preostale vrednosti koristeći preostale hiperparametre dobijene genetskim algoritmom. Takav TRPO algoritam uspešno konvergira ka dobrim rezultatima i rešava problem potrebe za menjanjem parametara u toku treniranja. Dužina trajanja treniranja je i dalje duga (9 dana), što je u poređenju sa $P P O$ algoritmom neefikasno rešenje. Grafici treniranja i prosečnog povrata po epohama optimizovanog TRPO algoritma dati su na [8].

\section{ZAKLJUČAK}

Kao što se može videti u radu, algoritmi dubokog učenja sa potkrepljenjem mogu biti efektivni za rešavanje problema učenja robota da hoda, te oba primenjena uspešno rešavaju postavljeni problem.

Kao ideja za rešavanja efikasnosti TRPO algoritma uz pomoć genetskog algoritma, definitivno bi potreba bila koristiti više iteracija po svakom kandidatu (reda par stotina pa možda čak i do hiljada), jer tek tada bi genetski mogao da pronađe rešenje koje će da efektivno trenira i na početnim epohama i posle nekoliko hiljada epoha i time se svrsta u rang efikasnosti kao što je to postigao PPO. Ovo bi zahtevalo velike vremenske i računarske resurse da bi se izvršilo uspešno do kraja. Svakako, PPO kao algoritam je generalno bolji u odnosu na TRPO, što je takođe i pokazano kroz ovaj rad koliko je efikasniji $u$ treniranju.

\section{LITERATURA}

[1] Schulman, John, et al. "Trust region policy optimization." International conference on machine learning. PMLR, 2015.

[2] Fletcher, Roger. "Conjugate gradient methods for indefinite systems." Numerical analysis. Springer, Berlin, Heidelberg, 1976. 73-89.

[3] Schulman, John, et al. "Proximal policy optimization algorithms." arXiv preprint arXiv:1707.06347 (2017).

[4] https://gym.openai.com/

[5] https://pybullet.org/wordpress/

[6] https://pytorch.org/

[7] https://github.com/reinai/HumanoidRobotWalk

[8]https://github.com/sovaso/GeneticAlgorithmForHuman oidRobotWalk

[9] Reynolds, Douglas A. "Gaussian mixture models." Encyclopedia of biometrics 741 (2009): 659-663.

[10] Gao, Bolin, and Lacra Pavel. "On the properties of the softmax function with application in game theory and reinforcement learning." arXiv preprint arXiv:1704.00805 (2017).

\section{Kratka biografija:}

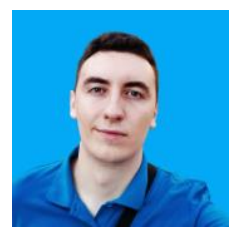

Vasilije Pantić rođen je u Novom Sadu 1997. god. Master rad na Fakultetu tehničkih nauka iz oblasti Elektrotehnike i računarstva - Softversko inženjerstvo odbranio je 2021.god.

kontakt: vpantic10@gmail.com 